\title{
Effect of Fly Ash and SiC Particles on Hardness and Microstructure of Friction Stir Welded MMCs
}

\author{
Sachinkumar, S. Narendranath and D. Chakradhar
}

\begin{abstract}
Metal matrix composites (MMCs) constitute an important class of design and weight efficient structural materials that are encouraging every sphere of engineering applications. Since, there has been an increasing interest in composites containing low density and low cost reinforcements. In the present work, Friction Stir Welding (FSW) has been used to join the AA6061 reinforced with SiC and Fly-Ash hybrid metal matrix composites (MMCs). Accordingly, rectangular composite plates were fabricated through stir casting route, then these plates were welded by using FSW. Micro-structural characterization of the stir zone was carried out through Optical Microscopy (OM). The uniform grain distribution was observed across the stir zone of AA6061/SiC/Fly-Ash composites after FSW. In addition, the evaluation of hardness was carried out and observed that a considerable increase in the hardness in the weld nugget zone when compared to the base metal for all percentage composition of fly Ash particles across the stir zone resulting successful method for FSW of AA6061/SiC/Fly-Ash composites has been developed.
\end{abstract}

Keywords--- Friction Stir Welding, Hardness, Microstructure, MMCs, Fly-ash, Silicon Carbide

\section{INTRODUCTION}

$\mathrm{M}$ ETAL Matrix Composites (MMCs) are fetching very attractive automotive, aerospace, marine and many other applications due to their admirable physical and mechanical properties [1],[2],[3]. Among MMCs the particle reinforced aluminum matrix composites (AMCs) are really attractive because of their low cost, isotropic properties [4], [5].

In order to broaden the wide utilization of AMCs, effective and efficient joining techniques such as solid state welding and fusion welding become of practical importance. However it is difficult to achieve defect free welds by employing conventional fusion welding techniques due to the presence of ceramic particles, problems such as incomplete mixing of parent and filler material and deleterious chemical reaction between reinforcement and parent metal, the presence of porosity, and formation of excess and deleterious phases are difficult to avoid in the joints produced by conventional fusion welding methods [6],[7]. In such cases, solid state welding methods are highly desirable to achieve potentially good AMC joints.

As a solid state welding technique, friction stir welding (FSW) is a rapidly developing and has proved to be successful and effective welding method for joining Aluminum alloys [8], [9]. It is considered a promising welding method for joining of AMCs because the drawbacks of fusion welding can be avoided in FSW. In the past few years, joining of AMCs using FSW was attempted and the microstructures and mechanical properties of the FSW joints were studied, including $\mathrm{Al}_{2} \mathrm{O}_{3} \mathrm{p} / \mathrm{AA7005}$ [10], [11], $\mathrm{Al}_{2} \mathrm{O}_{3} \mathrm{P}$ AA6061 [11], [12], ,13] ,[14], [15]. SiCp/AA2009 [16], [17], [18], [19]. $\mathrm{B}_{4} \mathrm{Cp} / \mathrm{AA} 6061$ [20], $\mathrm{TiB}_{2} \mathrm{P} / \mathrm{Al}$ [21], $\mathrm{Mg}_{2} \mathrm{Sip} / \mathrm{Al}-9.7 \mathrm{Mg}-5.5 \mathrm{Si}$ [22], and TiCp/Al [23]. FSW has been shown to result in a more homogeneous distribution of the particles and their breakup and bluntness due to the effect of severe plastic deformation and material mixing, furthermore, the grain sizes of the matrices were greatly refined due to dynamic recrystallization.

Although several studies on FSW of AMCs were reported, a small number of researches are also studied on FSW of hybrid AMCs, but no literature is available to study the effect of low cost reinforcement like fly ash on the welded strength using FSW.

In this study 6mm thick Al6061/SiC/Fly Ash composite plates produced by stir casting route are welded by Friction Stir Welding and then microstructure and hardness in the nugget zone were examined carefully.

\section{EXPERIMENTAL DETAILS}

The chemical compositions of Al6061 and Fly Ash are provided in Table 1 and Table 2 respectively. AA6061$10 \% \mathrm{SiC}$ reinforced with 3\% (wt.\%) Fly Ash composite was produced by stir casting process with bottom pouring arrangement. Plates of size $100 \mathrm{~mm}$ x $50 \mathrm{~mm}$ x $6 \mathrm{~mm}$ were prepared from cast composite using machining process. The butted plates were placed on a rigid backing plate and firmly held by means of a specially designed fixture. A nonconsumable rotating tool made of hot work too steel H13 with cylindrical threaded profile pin.
Sachinkumar, Research Scholar, Department of Mechanical Engineering, NITK, Surathkal, India.E-mail:sachindongapur1@gmail.com

S. Narendranath, Professor Department of Mechanical Engineering, NITK, Surathkal, India. E-mail:snnath88@yahoo.co.in

D. Chakradhar, Assistant Professor, Department of Mechanical Engineering, NITK, Surathkal, India. E-mail:chakradhar.dupadu@gmail. com

DOI: 10.9756/BIJIEMS.10415 
Table 1: Chemical Composition of Al6061

\begin{tabular}{|l|l|}
\hline Element & Weight\% \\
\hline $\mathrm{Mg}$ & 1.58 \\
\hline $\mathrm{Si}$ & 0.67 \\
\hline $\mathrm{Ti}$ & 0.2 \\
\hline $\mathrm{Cr}$ & 0.2 \\
\hline $\mathrm{Mn}$ & 0.22 \\
\hline $\mathrm{Fe}$ & 0.6 \\
\hline $\mathrm{Cu}$ & 0.27 \\
\hline $\mathrm{Zn}$ & 0.17 \\
\hline $\mathrm{Al}$ & Balance \\
\hline
\end{tabular}

Table 2: Chemical Composition of Fly ash particle

\begin{tabular}{|l|l|}
\hline Element & Weight \% \\
\hline $\mathrm{Al}_{2} \mathrm{O}_{3}$ & 30.06 \\
\hline $\mathrm{SiO}_{2}$ & 63.51 \\
\hline $\mathrm{MgO}$ & 1.54 \\
\hline $\mathrm{TiO}_{2}$ & 0.99 \\
\hline $\mathrm{Fe}_{2} \mathrm{O}_{3}$ & 3.9 \\
\hline
\end{tabular}

The welding process was carried out on a 10 tonns capacity ETA horizontal stir welding machine. The tool was inclined at an angle of $2^{\circ}$ backward with respect to normal of the workpiece. The rotating tool was plunged into the abutting edges of the plate until the shoulder touches the surface with sufficient plunge force. After a dwell period of 15 seconds, the machine table was moved at a predetermined welding speed. When the plunged tool reaches the other end, the tool was retracted. This process was repeated for different combinations of welding process parameters. Figure 1 represents the friction stir welding set up, Figure 2 represents the welded composite plates by FSW. The welded specimens were cross-sectioned perpendicular to the welding direction from joints. These specimens were polished with a diamond paste and finally etched with Keller's reagent. Then using Optical Microscope, microstructures of the welded joints at the nugget zone have been studied. Vickers hardness tester was used to measure the hardness of the welded specimen at nugget zones of the weld. The hardness tests were performed at three different places on the nugget zone and their mean is taken as final hardness number.

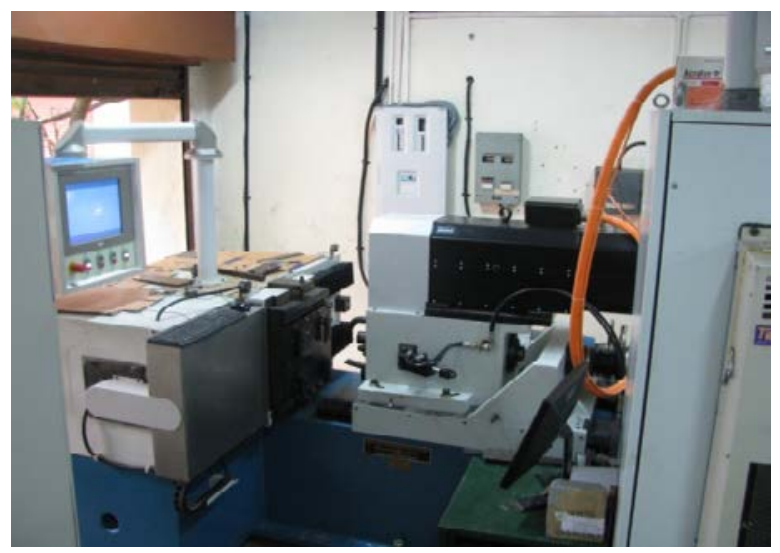

Fig.1: FSW Setup

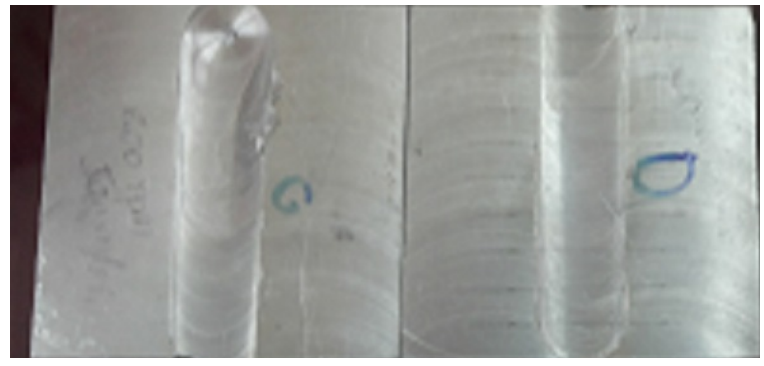

Fig. 2: Welded Composite Plates by FSW

\section{RESUlTS AND DISCUSSIONS}

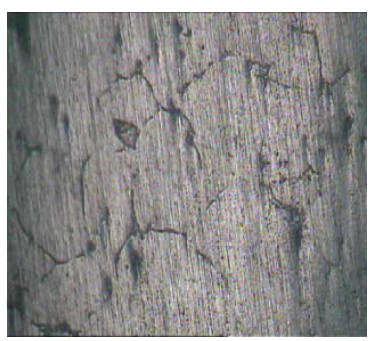

Fig.3(a)

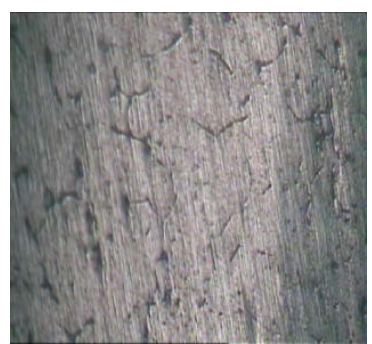

Fig.3(b)

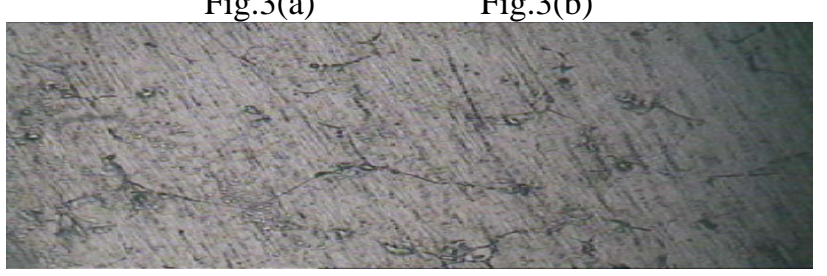

Fig. 3: (a) Welded AMCs Specimen, (b) Microstructure Image of Parent AMCs, (c) Microstructure Image of Welded Region

Optical Microscopy image of hybrid AMC parent material microstructure is shown in Fig. 3(a) and the microstructure of hybrid AMC after welding with various zones is shown in Fig. 3(b) and Fig. 3(c) shows microstructure of nugget zone. The parent AMC has a dendritic structure, as it is produced by using stir casting process. The dendritic structure of the parent metal shows dispersion of $\mathrm{SiC}$ particles in the AMC. The microstructure of FSW is classified into mainly three regions namely, heat affected zone (HAZ), thermomechanical affected zone (TMAZ), and weld nugget zone as shown in Fig. 3 (c) [24],[25],[26]. It clearly reveals the different grain sizes in the interfacial boundary between the TMAZ and weld nugget is shown in the fig 4 .

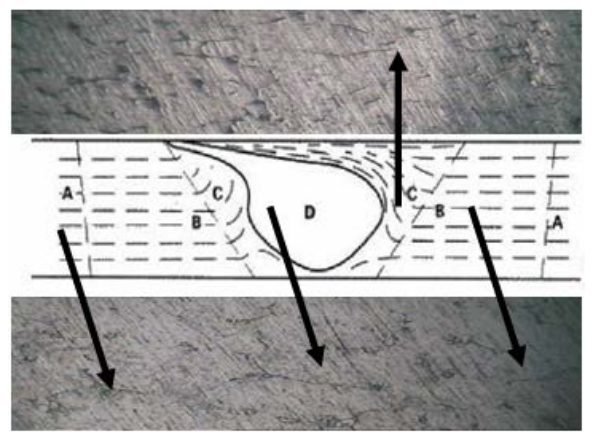

Fig. 4: FSW Weld Showing Four Distinct Zones: (A) Base Metal (B) Heat Affected (C) Thermomechanically Affected and (D) Stirred (nugget) Zone 
The weld nugget zone was a slightly larger than the size of the rotating pin, irrespective of width and height of the pin. On the other hand, the size of the zone will vary with frictional pressure, forging force and friction time. As the friction time is reduced, the large amount of thermal energy is propagated in the direction of work piece which will increase in the size of the nugget zone [24]. The weld nugget surrounded by TMAZ, having well deformed and elongated coarser grain due to the stirring action of the tool. However, in this region plastic deformation and dynamic recrystallisation is a bit lesser than weld nugget region. In this study, threaded cylindrical pin FSW tool is being used which provides energetic stirring action in the flowing material due to threads which results in formation of finer grains [27].

To characterize the hardness of the weld region of the FSW, Vickers hardness testing machine was used. The hardness of the nugget zone is found to be higher than that of the base composite irrespective of the tool rotation and weld traverse speed. The breakage of SiC particles and refinement of deformation strain [28]. Thus hardness values were found to be lower than nugget zone. The difference in hardness between the HAZ and SZ is attributed to the grain refinement in the stir zone and annealing process in the HAZ [26].

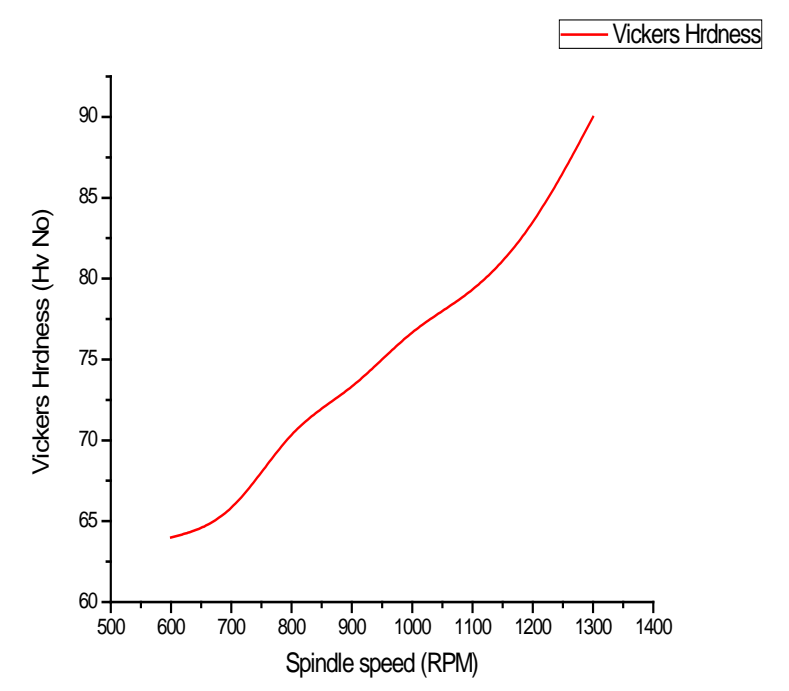

Fig. 5: Vicker’s Hardness at Nugget Zone v/s Spindle Speed

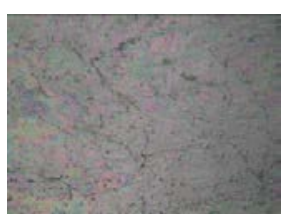

(a)600rpm

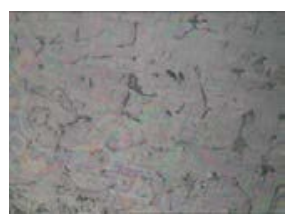

(c) $800 \mathrm{rpm}$

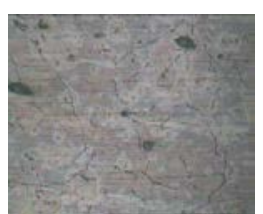

(b)700rpm

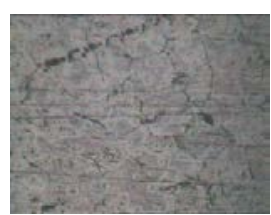

(d) 900rpm

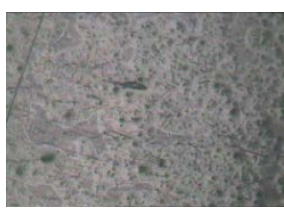

(e)1000rpm

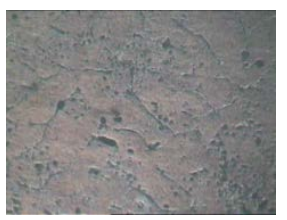

(g) $1200 \mathrm{rpm}$

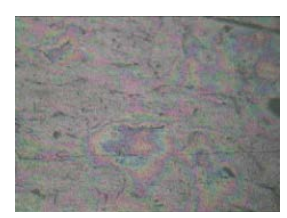

(f)1100rpm

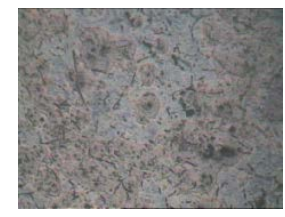

(h) 1300rpm
Fig. 6: Microstructure of Welded Zone at Various Spindle Speed of (a)600rpm (b)700rpm (c)800rpm (d)900rpm

(e)1000rpm (f)1100rpm (g)1200rpm (h)1300rpm

As the tool spindle speed is increases from 600rpm to 1300rpm, the hardness values are also increased at a traverse speed of $50 \mathrm{~mm} / \mathrm{min}$ as shown in the fig 5 . This is because, high rotational speed and low welding speed led to increased heat generation and reduced cooling rate, which results in uniform distribution of reinforcement particles.

\section{CONCLUSION}

The study demonstrates that, friction stir welding can be successfully adopted for joining Al6061/SiC/FA hybrid AMCs. The microstructure at the nugget zone was characterized by fine and uniform distribution of SiC and Fly ash particles. The clusters present in the parent composite were split by stirring action of the tool. The weld zone can exhibit higher hardness than parent material due to fragmentation, homogeneous distribution of $\mathrm{SiC}$ particles and grain refinement. In addition, the evaluation of hardness was carried out and observed that a considerable increase in the hardness in the weld nugget zone when compared to the base metal for all percentage composition of fly ash particles across the stir zone

\section{REFERENCES}

[1] I A Ibrahim, Mohamed FA, Lavernia EJ. "Particulate reinforced metal matrix composites -a review”. J Mater Sci ,26, 1137-56.1991.

[2] V K Lindroos, Talvitie MJ. "Recent advances in metal matrix composites”. J Mater Process Technol . 53, 273-84, 1995.

[3] S C Tjong, Ma ZY. "Microstructural and mechanical characteristics of in situ metal matrix composites”. Mater Sci Eng R, 29, 49-113, 2000.

[4] P Jin, Xiao BL, Wang QZ, Ma ZY, Liu Y, Li S. "Effect of hot extrusion on interfacial microstructure and tensile properties of SiCp/2009Al composites fabricated at different hot pressing temperatures”. J Mater Sci Technol, 27, 518-24, 2011.

[5] P Jin , Xiao BL, Wang QZ, Ma ZY, Liu Y, Li S. "Effect of hot pressing temperature on microstructure and mechanical properties of $\mathrm{SiC}$ particle reinforced aluminum matrix composites.” Acta Metall Sinica, 47, 298304, 2011.

[6] D Storjohann , Barabash OM, Babu SS, David SA, Sklad PS, Bloom EE." Fusion and friction stir welding of aluminum-metal-matrix composites.” Metall Mater Trans A , 36A, 3237-47,2005.

[7] X H Wang, Niu JT, Guan SK, Wang LJ, Cheng DF. "Investigation on TIG welding of SiCp-reinforced aluminum-matrix composite using mixed shielding gas and Al-Si filler.” Mater Sci Eng A, 499, 106-10, 2009.

[8] R S Mishra , Ma ZY. "Friction stir welding and processing”. Mater Sci Eng R ;50, 1-78, 2005. 
[9] R Nandan , DebRoy T, Bhadeshia HKDH. "Recent advances in frictionstir welding-process, weldment structure and properties". Prog Mater Sci, 53, 980-1023, 2008.

[10] L Ceschini , Boromei I, Minak G, Morri A, Tarterini F. "Effect of friction stir welding on microstructure, tensile and fatigue properties of the AA7005/ 10 vol.\% $\mathrm{Al}_{2} \mathrm{O}_{3}$ p composite". Compos Sci Technol, 67, 605-15, 2007.

[11] P Cavaliere , Cerri E, Marzoli L, Dos Santos J "Friction stir welding of ceramic particle reinforced aluminium based metal matrix composites". Appl Compos Mater, 11, 247-58, 2004.

[12] L M Marzoli , Strombeck AV, Dos Santos JF, Gambaro C, Volpone LM. "Friction stir welding of an AA6061/Al2O3/20p reinforced alloy". Compos Sci Technol, 66, 363-71, 2006.

[13] L Ceschini, Boromei I, Minak G, Morri A, Tarterini F. "Microstructure, tensile and fatigue properties of AA6061/20 vol. $\% \mathrm{Al}_{2} \mathrm{O}_{3} \mathrm{p}$ friction stir welded joints”. Composites Part A, 38,1200-10, 2007.

[14] G Minak, Ceschini L, Boromei I, Ponte M. "Fatigue properties of friction stir welded particulate reinforced aluminium matrix composites”. Int J Fatigue, 32, 218-26, 2010.

[15] J M Root , Field DP, Nelson TW. "Crystallographic texture in the friction-stirwelded metal matrix composite Al6061 with 10 vol pct $\mathrm{Al}_{2} \mathrm{O}_{3}$ ”. Metall Mater Trans A, 40A, 2109-14, 2009.

[16] D Wang , Xiao BL, Wang QZ, Ma ZY. "Friction stir welding of SiCp/2009Al composite plate”. Mater Des, 47, 243-7, 2013.

[17] A H Feng , Xiao BL, Ma ZY. "Grain boundary misorientation and texture development in friction stir welded $\mathrm{SiCp} / \mathrm{Al}-\mathrm{Cu}-\mathrm{Mg}$ composite”. Mater Sci Eng A, 497, 515-8, 2008.

[18] A H Feng, Xiao BL, Ma ZY. "Effect of microstructural evolution on mechanical properties of friction stir welded AA2009/SiCp composite”. Composite Science Technology, 68, 2141-8, 2008.

[19] Z Y Ma , Feng AH, Xiao BL, Fan JZ, Shi LK. “Microstructural evolution and performance of friction stir welded aluminum matrix composites reinforced by SiC particles”, Mater Sci Forum, 539-543, 3814-9, 2007.

[20] X G Chen , da Silva M, Gougeon P, St-Georges L. "Microstructure and mechanical properties of friction stir welded AA6063-B ${ }_{4} \mathrm{C}$ metal matrix composites”. Mater Sci Eng A, 518, 174-84, 2009.

[21] S J Vijay , Murugan N. "Influence of tool pin profile on the metallurgical and mechanical properties of friction stir welded Al-10 wt.\% TiB 2 metal matrix composite”. Mater Des, 31, 3585-9, 2010.

[22] H Nami , Adgi H, Sharifitabar M, Shamabadi H. "Microstructure and mechanical properties of friction stir welded $\mathrm{Al} / \mathrm{Mg}_{2} \mathrm{Si}$ metal matrix cast composite”. Mater Des, 32, 976-83,2011.

[23] S Gopalakrishnan , Murugan N. "Prediction of tensile strength of friction stir welded aluminium matrix TiCp particulate reinforced composite” ,Mater Des; 32, 462-7, 2011.

[24] A.H Feng, Xiao, B.L. \& Ma, Z. Y. "Effect of microstructural evolution on mechanical properties of friction stir welded AA2009/SiCp composite”. Compos. Sci. Technol, 68(9), 2141-2148, 2008.

[25] Hu, seyin Uzun.” Friction stir welding of SiC particulate reinforced AA2124 aluminium alloy matrix composite”. J. Mater. Des, 28(5), 1440-1446, 2007.

[26] R.Palaanivel, Koshy Mathews, P. \& Murugan, N. "Influences of tool pin profile on the mechanical and metallurgical properties of friction stir welding of dissimilar aluminum alloy”. Int. J. Eng. Sci. Technol, 2(6), 2109-2115, 2010.

[27] P.Bahemmat, Besharati M.K, Haghpanahi M.; Rahbari, A. \& Salekrotam, R. "Mechanical, micro-and macrostructural analysis of AA7075-T6 fabricated by friction stir butt welding with different rotational speeds and tool pin profile”. J. Eng. Manuf, 224 (B), 419-433, 2009

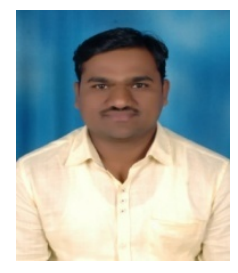

Sachinkumar graduated in mechanical engineering and received M.E in Manufacturing science and engineering from Bangalore University, Bangalore in 2012. Presently he is persuing $\mathrm{PhD}$ in Friction Stir Welding of MMCs at National Institute of Technology Karnataka, India. He presented Friction Stir Welding based papers in national and international conferences. His areas of interest include Friction Stir Welding, Machining and Casting.

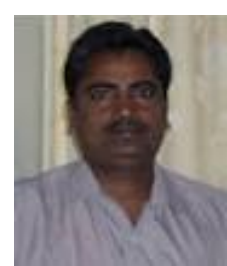

Dr.S.Narendranath graduated in Mechanical engineering from Mysore University of Karnataka. He received M.Tech from kuvempu university and $\mathrm{PhD}$ in Materials form IIT Kharagpur. Presently he is working as Professor in the department of mechanical engineering at National Institute of Technology Karnataka. His areas of Interest includes Advanced Manufacturing and Technology, Machining of advanced materials, Severe Plastic Deformation, Shape Memory Alloy, Welding technology.

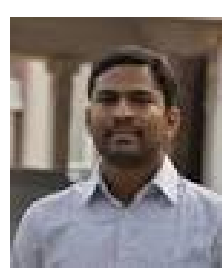

Dr.D.Chakradhar graduated in Mechanical engineering from SK University, Anantapur. He received M.Tech from National Institute of Technology Warangal and $\mathrm{PhD}$ in Non-Traditional Manufacturing from National Institute of Technology Warangal. Presently he is working as Assistant Professor in the department of mechanical engineering at National Institute of Technology Karnataka. His areas of interest include Non Traditional Manufacturing Processes Design of Experiments, Design for Manufacture. 